\title{
The Equilibrium Diagram of the Ti-Al System*
}

\author{
By Tomo-o Sato** and Yen-Chien Huang**
}

\begin{abstract}
The titanium-rich side phase diagram of the $\mathrm{Ti}$-Al system has been re-examined. Electrical resistance measurements, $\mathrm{X}$-ray analysis and microscopic observations were carried out to determine the equilibrium relations among the inter-solid phases. A partial phase diagram up to $50 \%$ Al by weight was constructed as shown in Fig. 16. The Al-saturated $\alpha$-Ti solid solution exists conjugately with the $\alpha_{2}$ phase for the temperature range below $1020^{\circ} \mathrm{C}$, at which temperature a peritectoid reaction, $\beta-\mathrm{Ti}+\alpha_{2} \rightleftharpoons \alpha$-Ti, takes place. The $\alpha_{2}$ phase exists in the range from 19 to $25 \% \mathrm{Al}$ by weight and it corresponds to $\mathrm{Ti}_{2} \mathrm{Al}$. One new phase named $\delta$ has been assumed to exist in the composition range from 26 to $34 \% \mathrm{Al}$ by weight at high temperatures.
\end{abstract}

The non-variant reactions in the solid alloys of this system were determined as follows;

\begin{tabular}{llccc} 
& & \multicolumn{2}{c}{ Composition } & \\
Name & Reaction & Ti $\%$ & Al $\%$ & Temperature \\
& ${ }^{\circ} \mathrm{C}$ \\
Peritectoid & $\beta-\mathrm{Ti}+\delta \rightleftharpoons \alpha_{2}$ & 78 & 22 & 1300 to 1400 \\
Peritectoid & $\beta-\mathrm{Ti}+\alpha_{2} \rightleftharpoons \alpha-\mathrm{Ti}$ & 92 & 8 & 1020 \\
Eutectoid & $\delta \rightleftharpoons \alpha_{2}+\gamma$ & 73.5 & 26.5 & 1050
\end{tabular}

\section{Introduction}

Aluminum has been found to be one of the most useful alloying elements for titanium-base alloys, because of, its high solubility in $\alpha$-Ti and low specific gravity, a remarkable increase of the strength-weight ratio of the alloys results. Therefore, the constitutional diagram of $\mathrm{Ti}$ - $\mathrm{Al}$ was and is very important in the course of industrial research on commercial titanium alloys for high tensile strength. Hence some informations concerning the constitutional diagram have already been published given by previous investigators. (1)(2) According to their investigations, the solubility limit of aluminum in $\alpha$-titanium at room temperature was about $25 \%$ and the first intermediate phase conjugated to $\alpha$-Ti solid solution was $\gamma$ phase. Fig. 1

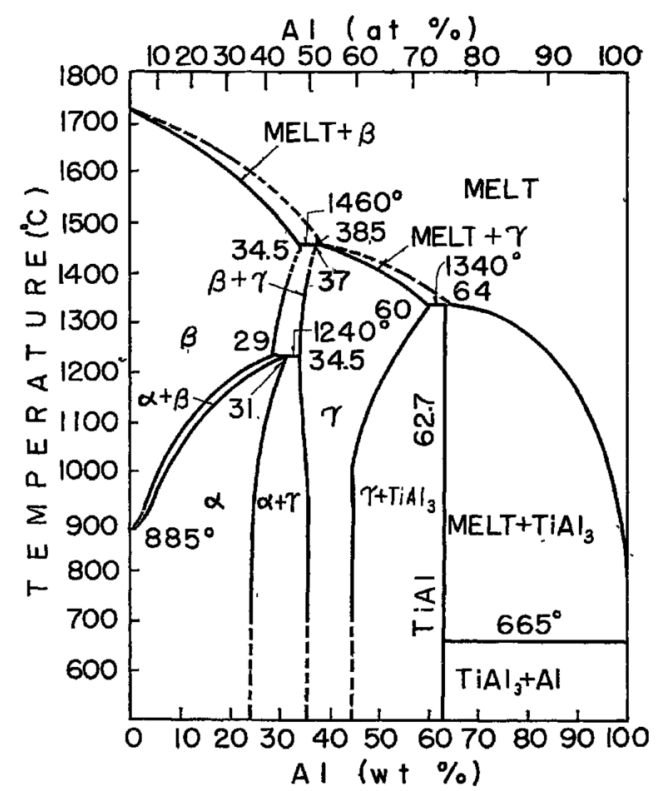

Fig. 1 Ti-Al phase diagram. (Af ter M. Hansen et al)

** Tomo-o Sato, The Institute of Technology, Nagoya, Japan. Yen-Chien Huang, Department of Metallurgy, Tohoku University, Sendai, Japan.

* This Manuscript was published in the Journal of Japan Institute of Metals, 23 (1959), 456.

\section{illustrates one of their results. (2)}

However, the solubility limit of aluminum in $\alpha-\mathrm{Ti}$ may be too high when it compared with the solubility limit of tin (3) which posseses similar physico-chemical properties as aluminum. In addition to the above, those alloys containing above $7.5 \% \mathrm{Al}$ displayed an abrupt embrittlement ${ }^{(4)}$ even in the so-called solid solution range.

This unfavorable abrupt embrittlement associated with $\alpha$-Ti solid solution has required the re-examination of the solubility limit of aluminum in $\alpha$-Ti.

Moreover, the latest researches have shown that certain intermediate phases ${ }^{(5)(6)}$ surely exist in Ti alloys containing from $8 \%$ to $20 \% \mathrm{Al}$, and the solubility limit of aluminum in $\alpha-\mathrm{Ti}$ was revised to about $6 \%$ at room temperature instead of $25 \%$. But no more information was available on the equilibrium relations between these new phases, $\alpha$-Ti solid solution and $\gamma$ phase other than an estimation by Zwicker. ${ }^{(6)}$

The present paper deals with the confirmation of a partial phase diagram of Ti-Al alloys containing up to $50 \% \mathrm{Al}$ by means of measuring the changes of electrical resistance of alloys against the temperature changes, because of an appreciable change of the electrical resistivity associates on the $\alpha \rightleftharpoons \beta$ transformation in titanium. (7) Besides, microscopic observations and X-ray analysis were also performed.

\section{Materials and Methods of Investigation}

(a) Materials, preparation of alloys and specimens

The titanium used in the present investigation was

(1) H. R. Ogden, D. J. Maykuth, W. L. Finlay, R. I. Jaffee : Trans. AIME, 191 (1951), 1150.

(2) E. S. Bumps, H. D. Kessler, M. Hansen: Trans. AIME, 194 (1952), 609.

(3) M. K. McQuillan: J. Inst. Metals, $84(1955 / 56), 307$.

(4) H. R. Ogden, D. J. Maykuth, W. L. Finlay, R. I. Jaffee : Trans. AIME, 197 (1953), 267.

(5) E. Ence, H. Margolin: J. Metals, 9 (1957), 484.

(6) K. Sagel, E. Schulz, U. Zwicker: Z. Metallk.,47(1956),529.

(7) F. M. Jaeger, et al : Proc. Roy. Acad. Amst., 39 (1936), 422. 
spongy in form which produced by the Kroll process at the Osaka Titanium Co. This spongy titanium was 99.7\% Ti and its Brinell Hardness Number was about 112 to 116 as-received. The purity of aluminum used was as high as $99.99 \%$.

The Ti-Al alloys were prepared by weighing about 70 to 100 grams for each charge and then pressed into compact briquettes, $30 \mathrm{~mm}$ in diameter after being well mixed. The briquettes were melted in an argon atmosphere in an arc furnace with $25 \mathrm{~V}$ and 600 to $700 \mathrm{~A}$. Button ingots were turned over and remelted several times. The twelve alloys produced were chemically analysed to compare with their weighed compositions. The results are shown in Table 1 . It shows that there is very little change of composition occurring during arc melting. The specimen number indicates the percentage of aluminum by weight in each alloy, such as, A-6 shows an alloy containing 6 $\% \mathrm{Al}$ by weight. A water-cooled copper crucible was used to obtain a flat button of about $30 \times 10 \times 60 \mathrm{~mm}$ in size, and all of the specimens required for further investigation were cut of $f$ from these buttons. A spark discharge machine ${ }^{(8)}$ was used to cut any desirable shapes of specimens, especially for alloys containing more than $10 \%$ of aluminum which were very hard to machine or cut. The schematic diagram of the spark

Table 1 Chemical analysis for several Ti-Al alloys.

\begin{tabular}{c|c|c}
\hline \hline Spec. No. & $\begin{array}{c}\text { Nominal composition } \\
\text { Al (\%) }\end{array}$ & $\begin{array}{c}\text { Chemical analysis } \\
\text { Al (\%) }\end{array}$ \\
\hline & & \\
A 6 & 6 & 6.05 \\
A10 & 10 & 10.25 \\
A 12 & 12 & 12.56 \\
A18 & 18 & 18.08 \\
A24 & 24 & 24.49 \\
A26 & 26 & 26.21 \\
A29 & 29 & 28.86 \\
A36 & 36 & 35.81 \\
A38 & 38 & 38.97 \\
A 40 & 40 & 40.39 \\
A46 & 46 & 45.86 \\
A50 & 50 & 48.65 \\
\hline
\end{tabular}

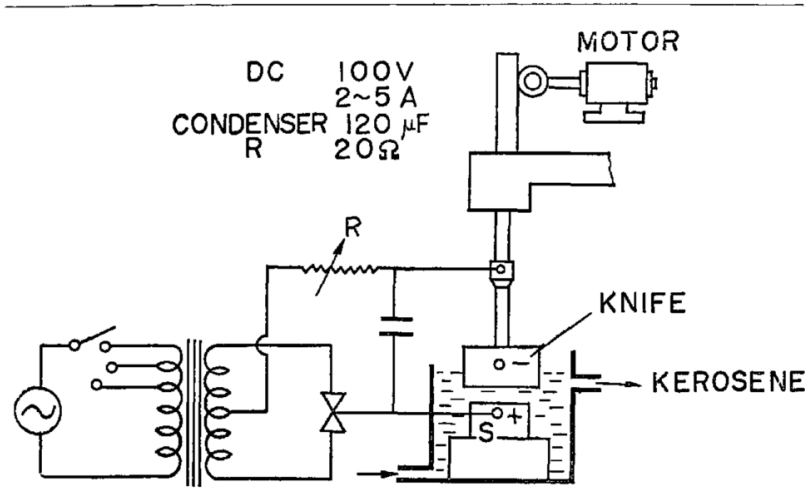

Fig. 2 Schematic diagram of a spark discharge machine.

discharge machine constructed by the authors is illustrated in Fig. 2. In which a sample $S$ is clamped to an anode and a brass plate used as a cutting knife is fixed to a cathode, and they are submerged in a kerosene bath. The cutting was done by a spark discharging

(8) K. Inoue: Text on techniques of electro-spark discharge, $3(1958)$. between the sample and the brass knife which was driven at a constant rate downward by a driving motor. Specimens after machining were electro-polished to clean the surface.

\section{(b) Procedure of electrical resistance measurement}

A specimen of about $2 \times 2 \times 60 \mathrm{~mm}$ in size prepared by the above procedure was spot welded to molybdenum lead wires, $0.5 \sim 1.0 \mathrm{~mm}$ in diameter and served to measure the change in the electrical resistance against the temperature change by the potential drop method. The specimen, with lead wires and a thermo-couple were sealed together into an alumina tube with one end closed and then heated in a furnace to a high temperature. The tube was evacuated to less than $1 \times$ $10^{-4} \mathrm{mmHg}$ up to 800 or $1000^{\circ} \mathrm{C}$ and purified argon gas was introduced at higher temperatures. Before measurement the specimen was kept in the $\beta$-phase region for 5 hrs and then the change in resistivity was measured at a constant cooling rate. Such measurement was repeated several times till the resistancetemperature curves coincided. Argon gas in the alumina tube was kept at a slightly positive pressure during the measurement up to $1450^{\circ} \mathrm{C}$. The error in resistance measurement due to thermoelectricity was eliminated by taking the mean of the results obtained by reversing the direction of electric current passed through the specimen. It was impossible to prevent a slight oxidation of the specimen but the resulting values were in close agreement.

\section{(c) Microstructures and X-ray analysis}

The alloy structures projected for microscopic observations were of two kinds, normal and quenched structures. The former was obtained from the specimens exposed to the same thermal cycles as that in the measurement of the electrical resistance. The other was of quenched specimens annealed at various temperatures for several hours by sealing in evacuated silica capsules. As an etchant, a mixed solution of 20 $\% \mathrm{HF}, 20 \% \mathrm{HNO}_{3}, 60 \%$ glycerine was used. X-ray patterns were taken by Debye-Scherrer's method with $\mathrm{Cu}-\mathrm{K} \alpha$ or Ti-K $\alpha$ using filed powder specimens obtained from pieces which had been served for electrical resistance measurements.

\section{Results and Discussion}

\section{(a) Electrical resistance-temperature curves}

Fig. 3 illustrates the temperature-electropotential curves for alloys containing 1 to $6 \% \mathrm{Al}$ and these results confirm the earlier information(1)(?)(9) that aluminum addition would produce an effect on raising the $\alpha \rightleftharpoons \beta$ transition temperature of pure.titanium.

Fig. 4 illustrates the curves for alloys containing 7 to $10 \% \mathrm{Al}$, and we find that there is a noticeable inflexion point in each curve in the range of lower temperatures from 200 to $700^{\circ} \mathrm{C}$ and the $\alpha \rightleftharpoons \beta$ transition temperature of each alloy raises to a higher

(9) E. I. Larsen et al : Met. Progr., 55 (1949), 359. 
temperature with increasing amounts of aluminum. This evidence could be explained in this way, that a phase, which has a low temperature coefficient of

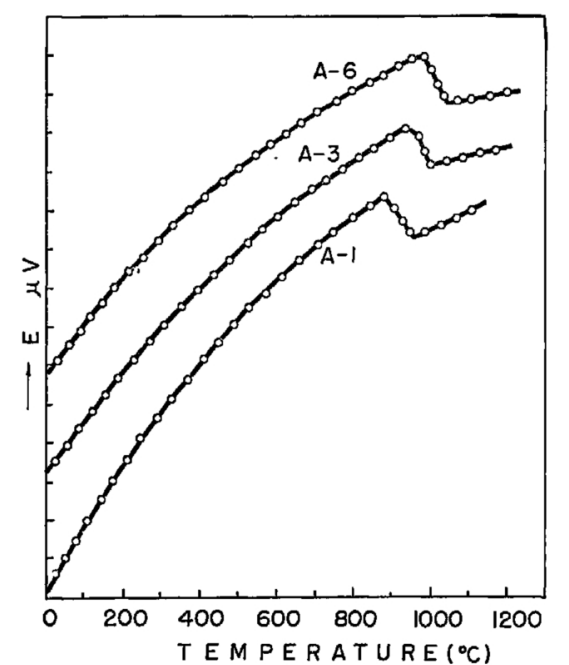

Fig. 3 Temp.-electropotential curves for typical alloys containing 1 to $6 \%$ Al. (Alloy number shows also percentage of $\mathrm{Al}$ content.)

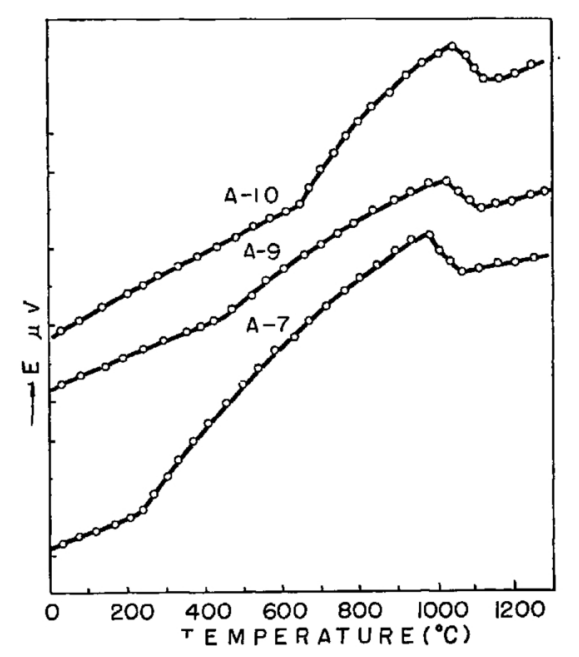

Fig. 4 Temp.-electropotential curves for typical alloys containing 7 to $10 \% \mathrm{Al}$.

resistivity, was precipitated from the $\alpha$-Ti solid solution matrix during cooling. The solubility limit of aluminum in $\alpha$-Ti determined from the present experiment is in good close agreement with the solubility limit of $\alpha_{2}$ phase in $\alpha$-Ti proposed by Zwicker. (6)

The results for alloys containing 12 to $18 \% \mathrm{Al}$ are presented in Fig. 5. Alloys in this composition range have a small temperature coefficient of resistivity, and each curve has an inflexion point turning upward at $1020^{\circ} \mathrm{C}$, and the maximum point of the curve shif ts with an increase in the aluminum content to higher temperatures. These evidences show that in these alloys a non-variant reaction takes place. Alloys containing 22 and $25 \% \mathrm{Al}$ as shown in Fig. 6 have a negative temperature coefficient of resistivity and have no inflexion points up to $1400^{\circ} \mathrm{C}$. The latter phenomenon suggests the fact that alloys in this composition range would have no phase transformation up to about $1400^{\circ} \mathrm{C}$. But, on the contrary, alloys containing 26 to
$29 \% \mathrm{Al}$ have a large positive temperature coefficient of resistivity and have an inflexion point turning upward at $1050^{\circ} \mathrm{C}$ and at higher temperatures, there

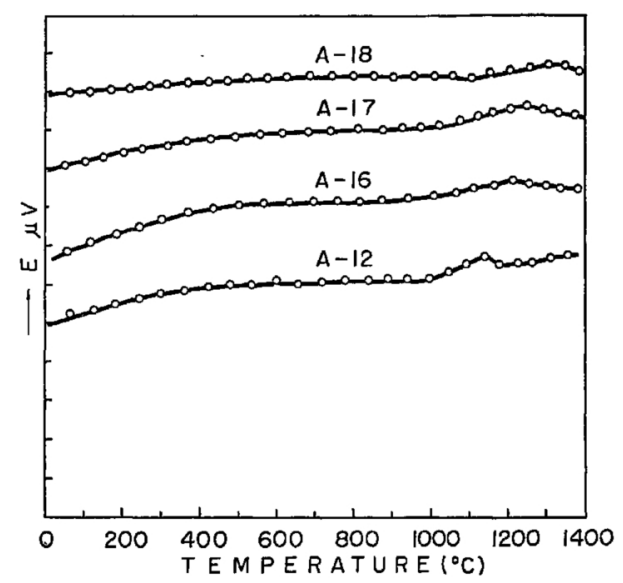

Fig. 5 Temp.-electropotential curves for typical alloys containing 12 to $18 \% \mathrm{Al}$.

are another inflexion points that level off sharply. The resistivity-temperature curves of these alloys show a great hysteresis loop on heating and cooling even

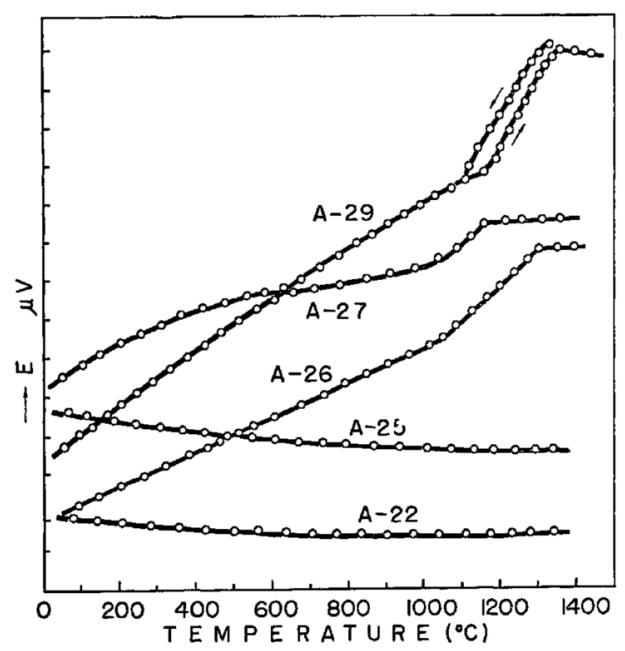

Fig. 6 Temp.-electropotential curves for typical alloys containing 22 to $29 \% \mathrm{Al}$.

at the rate of $1{ }^{\circ} \mathrm{C}$ per min. and the loop became smaller as the rate of heating and cooling became slower.

Fig. 7 illustrates typical temperture-resitivtiy curves for alloys containing 30 to $50 \% \mathrm{Al}$. The inflexion points of the curves for alloys A-30, A-34, A-48 and A-50 would indicate the solubility limit of the $\gamma$ phase. These portions of phase boundary obtained by the authors are in good agreement with the result published by Hansen. (2)

\section{(b) Microstructures}

The typical microstructures of alloys are summarized in Figs. 8 to 15 . Fig. 8 shows the microstructure of the $\alpha$ solid solution in the so-called basket-weave type, (10) obtained by furnace cooling. While normal structures of 15 to $18 \% \mathrm{Al}$ alloys have a typical

(10) A.D.McQuillan, M.K.McQuillan: Titanium, 452 page, Acad. Press. N. Y. (1956). 
peritectoid structure as shown in Fig. 9. Alloys containing from 19 to $25 \% \mathrm{Al}$ are entirely in a single phase at room temperature as shown in Fig. 10. This single phase is usually more resistive to the etchant than other alloys. Fig. 11 shows the as-cast structure

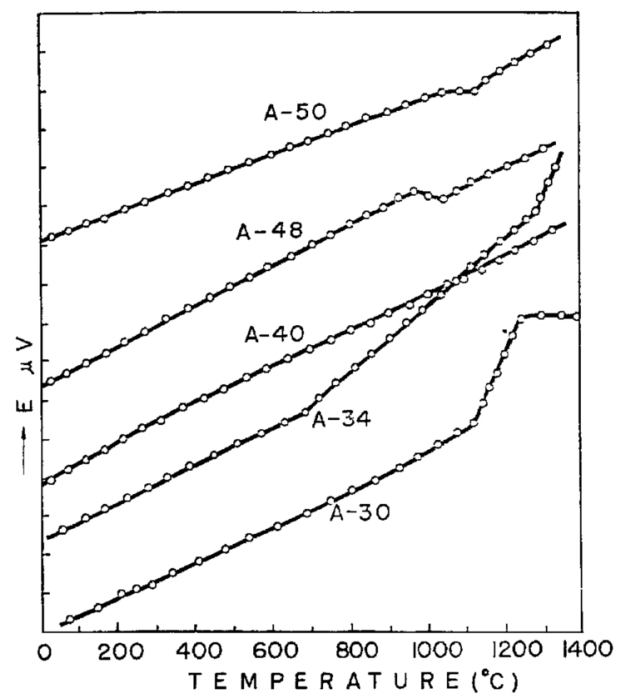

Fig. 7 Temp-electropotential curves for typical alloys containing 30 to $50 \% \mathrm{AI}$.

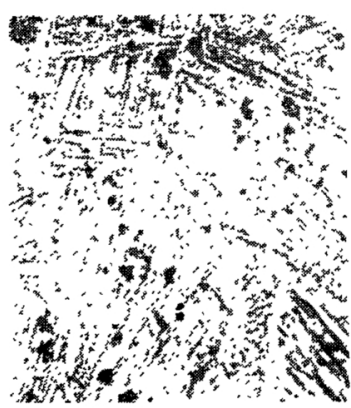

Fig. 8 Ti-4\% Al alloy, normal structure, $\alpha-\mathrm{T}_{i}$ in basket weave. $\times 100$

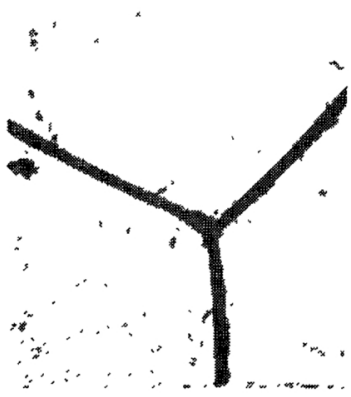

Fig. 12 Ti-27 \% Al alloy, water quenched after annealing at $1250^{\circ}$ for 3 hrs. $i$ phase. $\times 300$

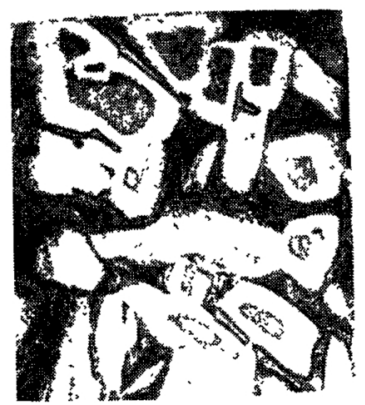

Fig. 9 Ti-17\% Al alloy, normal structure, $\alpha_{2}$ formed by $\boldsymbol{\beta}+\delta \rightleftharpoons \alpha_{2}$. $\times 100$

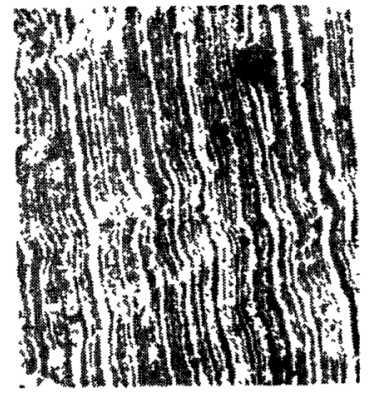

Fig. 13 Ti-27 \% Al alloy, $\alpha_{2}+\gamma$ in pearlitic structure, decomposed from $\delta$ phase. $\quad \times 165$ consisting of two phases, $\gamma$ (whitened) and $\delta$ (darkened) which are supposed to be related with the peritectic reaction. A normal structure of $40 \% \mathrm{Al}$ alloy which has entirely $\gamma$ phase is shown in Fig. 15.

\section{(c) X-ray diffraction}

$\mathrm{X}$-ray diffraction patterṇs were taken by DebyeScherrer's method with $\mathrm{Cu}-\mathrm{K} \alpha$ and Ti-K $\alpha$ to identif $y$ the alloy structures. The diffraction patterns of $\alpha$ solid solution, $\alpha_{2}$ and $\gamma$ phases agreed quite well with the results of previous works. $(1)(2)(6)$ However, the determination of the phase boundary between $\alpha$ solid solution and $\alpha_{2}$ phase by diffraction patterns was unsucessful because the figures were indistinct.

\section{(d) The phase diagram of the Ti-Al system in Ti-rich side}

A partial phase diagram of the Ti-rich side in the Ti-Al system has been constructed as shown in Fig. 16, by determination of the solid phase equilibria in the Ti-rich alloys with the above meationed methods, and with the aid of quotation data on liquid-solid relationships of previous references. (1)(2) Small circles on Fig. 16 show the data obtained from electrical

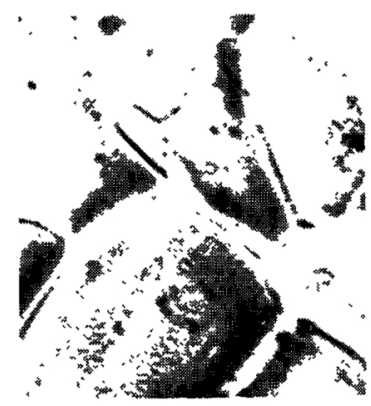

Fig. 10 Ti-25\% Al alloy, normal structure, $\alpha_{2}$ phase. $\times 300$

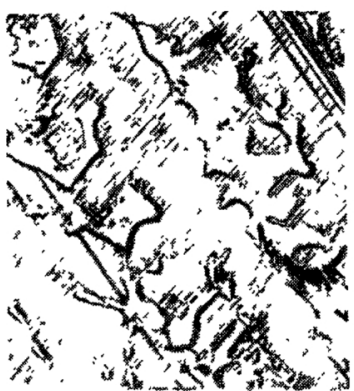

Fig. 14 Ti-36 \% Al alloy, are cast structure $\gamma$ and $\delta$ phases. $\times 165$

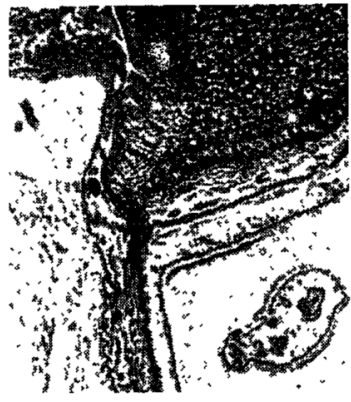

Fig. $11 \mathrm{Ti}-25 \% \mathrm{Al}$ alloy, arc cast structure. $\beta-\mathbf{T} \mathbf{i}+\delta$ phases. $\times 300$

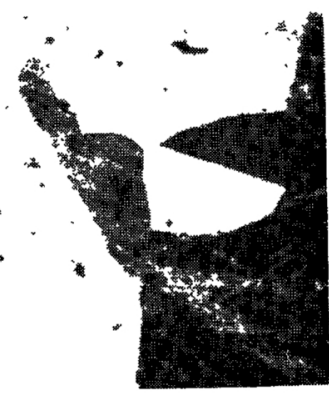

Fig. 15 Ti-40\% Al alloy, normal structure $\gamma$ phase. $\times 300$ of an alloy having the same composition as the alloy illustrated in Fig. 10. Both Figs. 12 and 13 are the microstructures of $27 \% \mathrm{Al}$ alloy submitted to different heat treatments, and Fig. 12 shows the water quenched structure from $1250^{\circ} \mathrm{C}$, and there is no doubt, that it shows a single phase, but the slowly cooled structure is of a pearlitic type as shown in Fig. 13. Fig. 14 shows the structure of $36 \%$ Al alloy

resistance measurements in the present investigation. The data on liquid-solid relalionships obtained from previous references are shown as follows;

$$
\begin{array}{ll}
\mathrm{L}+\beta-\mathrm{Ti} \rightleftarrows \delta & 1620^{\circ} \mathrm{C}, \mathrm{Ti} 72.5 \%, \mathrm{Al} 27.5 \% \\
\mathrm{~L}+\delta \rightleftarrows \gamma & 1460^{\circ} \mathrm{C}, \mathrm{Ti} 61.5 \%, \mathrm{Al} 38.5 \%
\end{array}
$$

Present investigation has confirmed the existence of an intermediate phase existing between 19 and 25 
$\% \mathrm{Al}$, that conjugates with $\alpha-\mathrm{Ti}$ in the temperature range below $1020^{\circ} \mathrm{C}$. This phase may agree with the $\alpha_{2}$ phase proposed by Zwicker. ${ }^{(6)}$ However, the $\alpha_{2}$ phase is better written as $\mathrm{Ti}_{2} \mathrm{Al}(11)$ than $\mathrm{Ti}_{3} \mathrm{Al}$ as given by

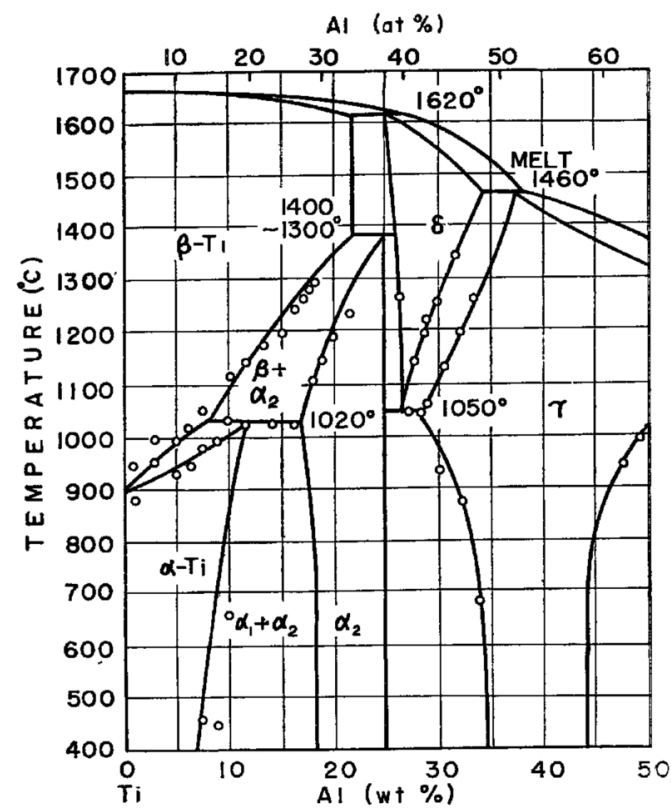

Fig. 16 Titanium-side equilibrium diagram of the Ti-Al system.

Zwicker, because the $\mathrm{Al}$ content in $\mathrm{Ti}_{3} \mathrm{Al}$ is $15.8 \%$ $\mathrm{A}]$ and $21.8 \% \mathrm{Al}$ for $\mathrm{Ti}_{2} \mathrm{Al}$. Another solid solution designated as $\delta$ has been assumed to exist between 26 and $34 \% \mathrm{Al}$ at high temperatures and it is may be based on $\mathrm{Ti}_{3} \mathrm{Al}_{2}$.

The non-variant reactions and solid phases existing in the alloys up to $50 \% \mathrm{Al}$ in the $\mathrm{Ti}$-Al system are summarized as follows;

(i) Non-variant reactions of inter-solid phases

Peritectoid reaction, $\beta-\mathrm{Ti}+\delta \rightleftarrows \alpha_{2} 1300$ to $1400^{\circ} \mathrm{C}$

$$
\text { Ti } 78 \%, \text { Al } 22 \%
$$

Peritectoid reaction, $\beta-\mathrm{Ti}+\alpha_{-} \rightleftarrows \alpha-\mathrm{Ti} 1020^{\circ} \mathrm{C}$

$$
\text { Ti } 92 \% \text {, Al } 8 \%
$$

Eutectoid reaction, $\delta \rightleftarrows \alpha_{2}+\gamma 1050^{\circ} \mathrm{C}$

$$
\text { Ti } 73.5 \%, \mathrm{Al} 26.5 \%
$$

\section{(ii) Solid phases}

$\alpha$-Ti solid solution: The primary solid solution of $\alpha-\mathrm{Ti}$ is produced after the peritectoid reaction (4), and the solubility limit of aluminum in the $\alpha$ phase is about $7 \%$ at $400^{\circ} \mathrm{C}$. The crystal structure is of hexagonal close-packed and the temperature coefficient of resistivity is positive and it will decrease as the aluminum content increases. On the contrary, the strength and hardness of this alloy increases with the aluminum content.(4)

$\alpha_{2}$ phase : $\alpha_{2}$ phase is an intermediate phase existing between 19 and $25 \% \mathrm{Al}$, which is produced after the peritectoid reaction (3). The crystal structure is of hexagonal close-packed, being the same as that of $\alpha$ solid solution. The temperature coefficient of

(11) F. A. Crossley, W. F. Carew: J. Metals, 9 (1957), 43. resistivity of most alloys are very slightly in positive, but some show a negative coefficient.

$\beta$ solid solution : $\beta$ solid solution is the primary solid solution of $\beta$-Ti and it exists at high temperatures. It's erystal form is expected to be body-centred cubic and the solubility of aluminum is about $22 \%$, at $1300^{\circ} \mathrm{C}$, but the $\beta$ solid solution in the $\mathrm{Ti}-\mathrm{Al}$ alloy can not be retained by quenching to room temperature at any aluminum concentrations.

$\delta$ phase $\delta$ phase is produced after the peritectic reaction (1), and decomposes into $\alpha_{2}$ and $\gamma$ aggregate at $1050^{\circ} \mathrm{C}$ as shown by reaction (5). But the rate of this transformation is quite slow, and the structure of resulting aggregate shows a pearlitic type. This phase can be completely retained by quenching and its temperature coefficient of resistivity is very small in positive or negative.

$\gamma$ phase $: \gamma$ phase is produced after the peritectic reaction (2). $\gamma$ has an ordered face-centred tetragonal structure, and is based on the composition TiAl. It's temperature coefficient of resistivity is positive and the portion of phase boundary can be detected clearly by the resistance measurement.

A complete phase diagram of the Ti-Al system was constructed as shown in Fig. 17 by combining the present partial diagram and previous data. (1)(2)

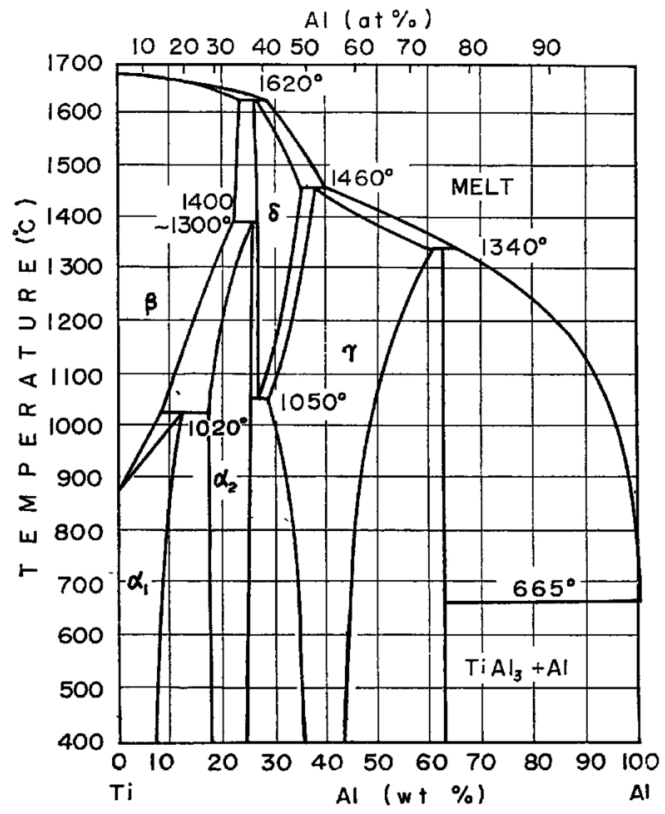

Fig. 17 Constitutional diagram of the Ti-Al system.

\section{Summary}

The phase diagram of the $\mathrm{Ti}-\mathrm{Al}$ system in titaniumrich side has been re-examined. Electrical resistance measurements, microscopic observations and X-ray analysis were carried out to determine the equilibria among inter-solid phases and a partial phase diagram up to $50 \% \mathrm{Al}$ was constructed as shown in Fig. 16. Moreover, with references to previous data, a complete phase diagram of the $\mathrm{Ti}-\mathrm{Al}$ system was constructed as shown in Fig. 17. The $\alpha_{2}$ phase is the first intermediate phase conjugated to $\alpha$-Ti for the temperature range below $1020^{\circ} \mathrm{C}$ and is based on $\mathrm{Ti}_{2} \mathrm{Al}$. The $\varepsilon$ phase $(18$ 
$\% \mathrm{Al}$ ) proposed by $\mathrm{Zwicker}^{(6)}$ was not detected in the present investigation.

The solid-phase equilibria is summarized as follows, the binary system is composed of seven solid phases, $\alpha$-Ti, $\alpha, \beta, \delta, \gamma, \mathrm{TiAl}_{3}$ and $\mathrm{Al}$, three non-variant reactions, two peritectoid and one eutectoid.
The authors are gratef ul to Dr. H.Kaneko, Professor of Tohoku University, Mr. A. Sawada, Managing Director of the Sumitomo Light Metal Co., Dr. K. Kosaki, Mr. Y. Kondo, of the Sumitomo Metal Co., for valuable suggestions, which greatly aided in the progress of the above experimental work. 